\title{
Supporting Students' Plans for STEM Careers: How Prepared are High School Educators in Appalachia to Help?
}

\section{Dr. Cheryl Carrico, Virginia Tech}

Cheryl Carrico is a Postdoctoral Research faculty member for Virginia Tech. Her current research focus relates to STEM career pathways (K-12 through early career) and conceptual understanding of core engineering principles. Prior to her current role, Dr. Carrico spent over 25 years in the aerospace industry conducting and leading R\&D, design engineering, and project management for composite aircraft components. Dr. Carrico received her B.S. in chemical engineering from Virginia Tech, Masters of Engineering from North Carolina State University, MBA from King University, and $\mathrm{PhD}$ in Engineering Education from Virginia Tech. Dr. Carrico is a certified project management professional (PMP) and licensed professional engineer (P.E.).

\section{Dr. Matthew Arnold Boynton PE P.E., Virginia Tech Department of Engineering Education}

Matthew Boynton recently finished his Ph.D in Engineering Education at Virginia Tech. He also holds a B.S. and M.S. in Civil Engineering from Tennessee Tech and an Ed.S in Instructional Leadership. Matthew has experience in industry as well as teaching. Previously, Matthew taught Project Lead the Way Engineering courses in two rural high schools in Appalachia. While at Virginia Tech, his research focused on understanding engineering career choice in the Appalachian region of the United States. Matthew is currently employed as an engineer at Bledsoe Telephone Cooperative, a rural telecommunications service provider in Pikeville Tennessee.

\section{Dr. Holly M Matusovich, Virginia Tech}

Dr. Matusovich is an Assistant Professor and Assistant Department Head for Graduate Programs in Virginia Tech's Department of Engineering Education. She has her doctorate in Engineering Education and her strengths include qualitative and mixed methods research study design and implementation. She is/was PI/Co-PI on 8 funded research projects including a CAREER grant. She has won several Virginia Tech awards including a Dean's Award for Outstanding New Faculty. Her research expertise includes using motivation and related frameworks to study student engagement in learning, recruitment and retention in engineering programs and careers, faculty teaching practices and intersections of motivation and learning strategies. Matusovich has authored a book chapter, 10 journal manuscripts and more than 50 conference papers.

\section{Dr. Marie C Paretti, Virginia Tech}

Marie C. Paretti is an Associate Professor of Engineering Education at Virginia Tech, where she codirects the Virginia Tech Engineering Communications Center (VTECC). Her research focuses on communication in engineering design, interdisciplinary communication and collaboration, design education, and gender in engineering. She was awarded a CAREER grant from the National Science Foundation to study expert teaching in capstone design courses, and is co-PI on numerous NSF grants exploring communication, design, and identity in engineering. Drawing on theories of situated learning and identity development, her work includes studies on the teaching and learning of communication, effective teaching practices in design education, the effects of differing design pedagogies on retention and motivation, the dynamics of cross-disciplinary collaboration in both academic and industry design environments, and gender and identity in engineering. 


\section{Supporting Students' Plans for Engineering Careers: How Prepared are High School Educators in Appalachia to Help?}

\section{Introduction}

Studies on high school student preparedness for college often consider student grade point averages and standardized test results as markers for predicting student success in college ${ }^{1-3}$. While such studies can inform researchers, educators, and regional education boards, limiting measures of student preparedness to the curriculum and standardized test requirements may not fully capture how prepared students are to attend college ${ }^{4-6}$. Specifically, such measures do not tracking students' understanding of career options, their knowledge about the higher education needed to support their career goals, and how to choose and apply to an appropriate college. In particular, prospective first generation college students from regions with low socioeconomic status (SES) often lack the knowledge of college-career connections and college application processes that is taken for granted by many non-first generation college-bound students who are not low SES ${ }^{7}$. This knowledge gap may contribute to high numbers of high school students in these regions saying they plan to attend college but not actually attending. The knowledge may be particularly important for first generation college students wishing to enter science, technology, engineering, and math (STEM) careers ${ }^{6}$. Such careers often require specific degrees not offered by all colleges and first generation college students may not have help from parents in understanding those requirements. Administrators, guidance counselors, and teachers (collectively referred to hereafter as educators) may be able to fill this gap, but current literature is relatively void of studies describing the abilities and confidence of educators in assisting students in considering careers and pathways to those STEM careers.

Our research is a first step toward such studies. As part of a larger NSF-funded project, we have developed and piloted an exploratory survey for high school educators to identify their understanding of college options and requirements relative to STEM, in particular, engineering, careers. The overall project is a mixed methods study designed to understand the barriers that inhibit students in the Appalachian region of the United States from pursuing engineering careers. The study used qualitative interviews ${ }^{8}$ grounded in Social Cognitive Career Theory $(\mathrm{SCCT})^{9,10}$ and Future Possible Selves (FPS) ${ }^{11,12}$ to explore the salient influences on students' career choice processes ${ }^{8,13}$. This phase revealed the importance of students knowing about engineering, being exposed to engineers and engineering work, and knowing the degree requirements for engineering careers ${ }^{14-18}$. We presented our findings to educators in the regions where data was collected to seek their perspectives and learn whether the findings resonated with their experiences. From these meetings, we identified three areas warranting further exploration through a survey to a larger group of educators: 1) educators' perceptions of students' awareness of engineering career and college preparation requirements, 2) educators' knowledge of and confidence in discussing engineering careers with students, and 3) educators' awareness of existing engineering interventions, if any, in the schools and local communities.

In this paper, we describe the development and pilot testing of a survey tool designed to gather the data necessary to explore these areas. Similar to the approaches taken by other researchers ${ }^{19,20}$, we used several research questions to guide survey development and testing: 
1) What are appropriate questions to capture educators' perspectives on students' knowledge of engineering careers and college requirements, their knowledge of and confidence in discussing engineering as a career choice, and their awareness of opportunities to expose students to engineering as a career choice?

2) To what extent does pilot data support the ability of the survey tool to obtain sufficient data to explore our identified gaps?

Our development and testing methods follow recommended practices.

\section{Background}

Students from rural Appalachia are underrepresented in higher education in general but particularly in engineering and other STEM fields ${ }^{18}$. Although literature on engineering career choice within Appalachia is limited, research does exist that identifies barriers these underrepresented students may face regarding engineering as a career choice, including limitations associated with exposure to STEM-related academic and social experiences ${ }^{21-28}$. For example, Dick ${ }^{29}$ indicates that the decision to major in a math or science intensive field comes through intrinsic and extrinsic values determined by past experiences. These experiences range from success in previous coursework to influences and expectations of socializers such as teachers, counselors, parents, and mentors ${ }^{29}$. Findings from Dick's study showed that both men and women who chose to major in engineering relied on the advice of parents and teachers more than their peers, and family influences were particularly strong for the participants in our project $^{16,17}$. Moreover, without early intervention and exposure, students can become disinterested in science and math, underestimate their abilities, and develop misconceptions about what type of person achieves a career in a STEM field ${ }^{30}$.

Importantly, current studies suggest that no single monolithic solution exists to introduce and recruit students into the engineering field. But one consensus among researchers regarding recruitment is to start early. Multiple studies have shown that early intervention is imperative as students begin to lose interest in math and science, limiting their career paths early in their education $^{31-34}$. The National Academy of Engineering recommends successful engagement of students in STEM subjects in grammar school ${ }^{35}$. However, Ross ${ }^{36}$ suggests that many early educators do not have the knowledge, attitudes, and behaviors to properly inform their students about engineering as a career choice.

The suggestion that educators may not have sufficient knowledge, attitudes, and behaviors to fully inform their students about engineering as a career choice is supported by findings in the first phases of this work. Qualitative interviews with high school students, college students, and working professionals regarding their experiences with engineering career choice indicate that educators within the secondary school system may lack critical knowledge necessary to introduce students to this field $8,16,17$. These findings support the need to explore educators' understanding of engineering as a career choice to support future efforts to increase STEM pathways within rural areas of Appalachia. 


\section{Method}

To support this goal, we developed an online survey tool and pilot-tested it with educators in selected areas of rural Appalachia in Tennessee and Virginia. In this section, we describe the survey development and the pilot test sample population.

\section{Survey Tool Development}

The exploratory nature of our overall research and the specific questions guiding the educator survey supported both closed- and open-ended questions. The closed-ended questions were constructed to address the three target content areas: 1) perceptions of students' awareness of engineering career and college preparation requirements, 2) knowledge of and confidence in discussing engineering careers with students, and 3) awareness of existing engineering interventions, if any, in the schools and local communities. We used open-ended questions to probe for additional exploratory information in each content area.

We followed a process for survey development suggested by Rea and Parker ${ }^{37}$. We completed the following steps:

1. Compare and map the constructs of interest for the survey tool to the guiding framework for the study (i.e., SCCT and FPS).

2. Develop a list of possible questions worded to represent the perspective of the survey participants.

3. Review the questions for a) word choice and question meaning, b) initial agreement on relevance to a construct area, and c) comparison with other questions in the construct grouping.

4. Estimate the time it would take for participants to fully answer all questions. We were aiming for a survey with an average response time of 15 minutes ${ }^{37}$. The length of questions, including number of sub-questions, were adjusted, as necessary, to support the intended 15-minute response time. For example, questions were organized using matrix formats with a leading question followed by a series of items (e.g., "I am familiar with..." followed by a list of programs).

5. Request reviews of the questions by engineering education professionals with survey experience and/or knowledge of the survey population of interest (e.g., high school educators in rural Appalachia) for format, question organization, question wording, and response choices. The key adjustment during this step was improvement of question neutrality, i.e., being sure questions did not appear inherently positive or negative.

6. Conduct a focus group review of the questions with experts knowledgeable about survey research, K-12 education, rural Appalachia, and our constructs of interest. The primary adjustment during this step was improving the text that introduced questions. For example, clarifying the request for survey takers to answer based on his or her experience or for the community in which he or she lives.

7. Deploy a pilot test of the survey to check the quality of construction. The pilot was purposely launched to two counties with high schools of varied characteristics in an attempt to represent the study's general population. Because this step is not intended to provide statistical accuracy, small numbers of respondents are acceptable ${ }^{37}$. 


\section{Survey Questions}

As a result of steps 1-6, the pilot survey deployed in step 7 contained, in order, 14 closed-ended attitudinal questions, 7 open-ended questions, and 5 closed-ended demographic questions. Corresponding to the three content areas represented in our research question, examples of questions for each are shown below.

\section{Educators' perceptions of student awareness of engineering}

The pilot survey included five closed-ended questions and three open-ended questions in this area. Closed-ended questions used a five-point Likert scale with appropriate attitudinal response categories (e.g., strongly disagree to strongly agree and not at all important to extremely important). Sample questions included the following:

- "Please indicate your perception of how important the following items are as high school students make career choices," followed by seven sub-items, including availability of a local job, job stability, level of pay, interest in the career, knowing someone in the career field, and the amount of formal education required.

- "High School Students have knowledge of...," with four sub-items listed.

Open-ended questions sought to more fully explore educators' understanding and included questions such as, "Why do you think students pursue engineering?"

\section{Educators' self-reported knowledge of and confidence in talking about engineering careers}

We used four closed-ended questions and two open-ended questions in this area. Closed-ended questions included such items as, "How much confidence (using a four point Likert scale) do you have in your ability to talk to high school students about..." followed by four sub-items. Another question asked participants to rate their familiarity with career programs such as those for engineering, medicine, pharmacy, nursing, and teaching (common career plans among participants in our study).

Open-ended questions were more exploratory such as, "What activities would you want to help you gain knowledge about STEM fields and careers?"

\section{$\underline{\text { Awareness of STEM and engineering interventions }}$}

In this area, we asked about existing interventions, but also asked about the sufficiency of these interventions as well as possible additional interventions using six closed-ended and two openended questions.

Two closed-ended questions were associated with knowledge of and use of intervention programs, including, "How familiar are you with each item?" followed by eight sub-items (e.g., 4-H activities, First Lego League, Project Lead The Way, and Technology Student Association). Participants were asked about their familiarity (unfamiliar or familiar) and whether they had used the program. The term "used" was intended to have a broad meaning, including using the program as part of a lesson plan, as an after-school activity they support, or had used it as a 
participant. The intent was to gain information on knowledge beyond knowing of a program to application of the program.

One of two the open-ended questions was designed to elicit participants' knowledge and preference of interventions as well as to gain recommendations on preferred programs by asking the participants to share best practice outreach initiatives.

Four closed-ended questions were related to existing efforts within schools and efforts that could be added (e.g., "Should additional promotion of engineering occur at your school?" with possible answers ranging from definitely not to definitely yes). Follow-on questions occurred depending on the respondent's response. Participants responding "definitely yes" were asked why they thought additional promotion should occur and participants responding "definitely not" were asked why not.

The related open-ended question asked the respondents what recommendations they have to tailor STEM programs to make them relevant for students in Appalachia.

\section{Participants}

Participants for the pilot data collection were purposely selected based on county characteristics $^{16,17}$. We selected one county from Tennessee and one county from Virginia. In addition, the two counties selected included a high school that offered Project Lead the Way (high school engineering curriculum), a small high school included in the student interview portion of the larger research project, and a large high school not included in the high school student interview process but within a county that participated in the educator meetings described in the introduction. Survey distribution and data collection were accomplished electronically using Qualtrics survey software. The request for piloting the survey was in accordance with our Institutional Review Board (IRB) approval and the county superintendents.

Our initial request yielded 8 responses, with demographic questions completed by all. To date, we have an approximately equal response rate between the pilot counties. Teachers represent $63 \%$ of respondents, $25 \%$ guidance counselors, and $13 \%$ principals. Females represent $75 \%$ and male $25 \%$ of the respondents. The final demographic question asked for the number of years the participant worked in the public school system. The average years worked by the respondents was from 16 to 20 years with a high of more than 36 years and the least from 6 to 10 years. The demographic information is illustrated in Tables 1 and 2.

Table 1. Primary Job Function of Pilot Questionnaire Participants

\begin{tabular}{|l|c|c|c|}
\hline Answer & Response & $\%$ \\
\hline Teacher & 5 & $63 \%$ \\
Guidance Counselor & 2 & $25 \%$ \\
Principal & 1 & $13 \%$ \\
Administrative Office & 0 & $0 \%$ \\
Other, please indicate & & 0 & $0 \%$ \\
\hline Total & & 8 & $100 \%$ \\
\hline
\end{tabular}


Table 2. Respondent's Number of Years Working in the Public School System

\begin{tabular}{|l|c|c|c|}
\hline Answer & & Response & $\%$ \\
\hline $0-5$ years & & 0 & $0 \%$ \\
$6-10$ years & 2 & $25 \%$ \\
$11-15$ years & 0 & $0 \%$ \\
16 - 20 years & 4 & $50 \%$ \\
$21-25$ years & 0 & $0 \%$ \\
26 - 30 years & 1 & $13 \%$ \\
$31-35$ & 0 & $0 \%$ \\
36 or more years & 1 & $13 \%$ \\
\hline Total & & 0 & $100 \%$ \\
\hline
\end{tabular}

Analysis

To support survey development, our research questions focused on the capability of the survey to gather information on the three target content areas. Therefore, our analysis did not focus on interpreting the results of individual questions, but rather on the quality of the responses, including descriptive statistics regarding variety of participant characteristics, response rate of questions within the survey, and use of the full scale of response choices.

\section{Quality of Research}

The quality of research was guided by recommendations from multiple sources ${ }^{37-39}$. Face validity of this pilot study was improved by including reviewers who represent the participant demographics, engineering education researchers, and people unfamiliar with engineering education. These reviewers were asked to report their interpretation of the meaning of each question, including the main questions as well as all sub-items. Reviewers were also asked about clarity, parallelism of flow, vocabulary, and sentence structure.

Pilot testing further promotes quality in survey development; therefore, pilot test results (described in the next section) will be used to improve items as needed prior to launching the full survey.

\section{Limitations of Research}

The primary limitation of this research is the number of respondents. While acceptable for the research questions we addressed, additional respondents could have helped ensure the representativeness of the content. However, we are studying rural regions and the average number of teachers and students is approximately one-half the national average ${ }^{40}$; thus, the number of possible respondents from two counties is fewer than the national average.

\section{Results}

Results of our pilot test suggest that our survey is sufficient for its intended purpose. The pilot survey results show a variety of participant demographics, including men and women teaching a variety of classes (e.g., science, English, math). Although the survey was slightly longer than we 
had anticipated, all participants who started the survey completed it. The average response time was 17 minutes with a median time of 16 minutes. Response rates for the open-ended questions ranged from $37 \%$ to $88 \%$.

\section{Closed-ended Questions}

All closed-ended questions were answered (including all demographic questions). As described above, the closed-ended questions used a variety of formats and response types, including 5point Likert scales, 4-point Likert scales, familiarity, and use scales. One measure of good survey design is that the full range of responses is used collectively by respondents ${ }^{37}$. Within the main questions, response usage ranged from a high of all options for some questions to a low of three out of five choices for others. For example, the question, "Please indicate your perception of how important the following items are as high school students make career choices" contained seven sub-questions. For four of those items, respondents used 3 of the 5 Likert responses; no participant selected "not at all important" or "very unimportant." Comparatively, for the question "High School Students have Knowledge of...," responses used all 5 Likert response options for two of the four sub-questions, and four of five response options for the other two.

Specifically, the results from the two questions listed above are shown in Table 3.

Table 3. Example Responses for Closed-ended Questions

Please indicate your perception of how important the following items are as high school students make career choices

\begin{tabular}{|c|c|c|c|}
\hline \# & Question & $\begin{array}{l}\text { Number of response } \\
\text { options used }\end{array}$ & Mean \\
\hline $\mathbf{1}$ & Availability of a local job & 2 of 5 & 4.38 \\
\hline 2 & Job stability & 3 of 5 & 4.25 \\
\hline 3 & Level of pay & 3 of 5 & 4.13 \\
\hline 4 & Interest in the career & 3 of 5 & 4.25 \\
\hline 5 & Parent/Legal Guardian support of the student & 3 of 5 & 4.13 \\
\hline 6 & Knowing someone who works in the career field & 3 of 5 & 4.13 \\
\hline 7 & $\begin{array}{l}\text { The amount of formal education required for different } \\
\text { college degrees }\end{array}$ & 2 of 5 & 4.25 \\
\hline \multicolumn{4}{|c|}{ High School students have knowledge of... } \\
\hline \# & Question & $\begin{array}{l}\text { Number of response } \\
\text { options used }\end{array}$ & Mean \\
\hline 1 & High School courses needed for their career & 5 of 5 & 3.25 \\
\hline 2 & The post-secondary education required for their career & 4 of 5 & 3.63 \\
\hline 3 & Careers currently available to them & 5 of 5 & 3.13 \\
\hline 4 & Careers related to their parents' careers & 4 of 5 & 3.63 \\
\hline
\end{tabular}

Several closed-ended questions had logical open-ended follow-up questions to allow explanations related to an extreme (a 1 or a 5) response. For example, the question shown in Table 4 had follow-ups for "definitely yes" and "definitely not" responses. Responses for "definitely yes" are shown in Table 5. 
Table 4. Example of question with linked follow-up questions

\section{Should (additional) promotion of engineering careers occur at your school?}

\begin{tabular}{|l|c|c|}
\hline Answer & & $\%$ \\
\hline Definitely yes & $43 \%$ \\
\cline { 2 - 3 } Probably yes & & $57 \%$ \\
Probably not & & $0 \%$ \\
\hline Definitely not & & $0 \%$ \\
\hline Total & & $100 \%$ \\
\hline
\end{tabular}

Table 5. Follow-up question and responses for "definitely yes"

Why do you think additional promotion of engineering should occur at your school?

\section{Text Response}

Had it in the past, was very successful due to many students choosing to pursue Engineering as a result of the course.

In the rural area that we live in, most of our students have heard of engineering, but probably none of them actually know and understand what the job entails.

There are few to no engineers living/working in our community. I don't currently know of any.

\section{Open-ended Questions}

The purpose of the open-ended questions was to gain deeper information in each of the content areas. Responses suggest that respondents thoughtfully completed these sections, thereby demonstrating their value. As examples, responses to two of the open ended questions are shown below in Table 6. Phrases related to barriers included "smart enough," "fear of math," and "lack of exposure." Reasons for pursuing engineering included interest in science and math, salaries, and mentors. 
Table 6. Sample open-ended questions

\section{What barriers prevent students from pursuing an engineering degree?}

\section{Text Response}

Getting accepted in engineering programs

Not strong in math

Lack of encouragement from home and lack of knowledge about the variety of engineers

Fear of math, think they are not smart enough, not enough support during first semesters of college

Lack of knowledge

Lack of exposure, lack of confidence, lack of support

\section{Why do you think students pursue engineering?}

\section{Text Response}

Interest in science and math

Because they are good at math and think they will make a big salary

Promoted as a high paying career, or student like a class/project dealing with engineering

Parent

Interest and ability with problem solving skills, families or mentor who encourages and supports student goals

\section{Discussion and Conclusions}

We set out to develop a survey to explore potential gaps between educators' knowledge and perception of engineering as it relates to Appalachian high school students' career choices and curricula. Our systematic approach to the survey development process has yielded a viable questionnaire. Our existing community network enabled us to pilot the survey at relevant sites and solicit a wide variety of potential respondents; this network can now be used to refine the questions for deployment to a larger population.

The expert reviews and pilot data demonstrate that a survey is capable of obtaining the data necessary to explore our three identified gaps. Specifically, our first research question asked about appropriate ways to ask about these gaps and our second question asked whether the pilot data supported the capability of the survey tool. In response to this question, our combination of closed- and open-ended questions nearly met our goal of a 15-minute survey duration, contained questions in each of three content areas, and appears to contain questions participants are willing and capable of answering.

Though the number of responses is limited, willingness of superintendents to allow participation and variation in respondent demographics suggest community interest in the survey. The interest is further supported given that all respondents completed the survey and answered the openended questions. The varied participant demographics indicates that educators both new to their career and approaching retirement are willing to participate. Also, participation reaches beyond engineering teachers and beyond teachers affiliated with traditional STEM courses. As the movement to integrate engineering into existing curricula increases, it is encouraging to know 
that educators outside of these courses are willing to participate in our research, and thus are potentially interested in supporting students' pursuit of STEM careers.

Following wider deployment, results from this survey will then be compared to key findings from qualitative work previously reported by the authors ${ }^{13}, 18,41,42$, including findings related to the importance of factors such as exposure to engineering, interest in engineering (more so than other career choices), local employment opportunities, and first generation college status. Importantly, the language used in the open-ended responses during the pilot appears sufficient to support such thematic comparisons and enable the team to use existing codebooks to analyze these responses. Although the number of pilot responses limits our ability to fully test these codebooks on the responses, our preliminary review suggests meaningful overlap.

Remaining pilot data is planned for collection and analysis in early 2015 along with any changes deemed necessary. Deployment of the final survey to the larger participant population is planned for the spring of 2015 .

\section{Acknowledgements}

This paper is based on research supported by the National Science Foundation under Grant No. EEC-1232629. Any opinions, findings, and conclusions or recommendations expressed in this material are those of the authors and do not necessarily reflect the views of the National Science Foundation.

\section{Bibliography}

1. Boden, K., Perceived academic preparedness of first-generation latino college students. Journal of Hispanic Higher Education, 2011. 10(2): p. 96-106.

2. Palardy, G.J., High School Socioeconomic Segregation and Student Attainment. American Educational Research Journal, 2013. 50(4): p. 714-754.

3. Rowan-Kenyon, H.T., L.W. Perna, and A.K. Swan, Structuring opportunity: The role of school context in shaping high school students' occupational aspirations. The Career Development Quarterly, 2011. 59(4): p. 330-344.

4. Conroy, C.A. Predictors of occupational choice among rural youth: Implications for career education and development programming. in American Educational Research Association. 1997. Chicago, IL: Paper presented at the Annual Meeting of the American Educational Research Association (Chicago, IL, March 24-28, 1997).

5. Turner, S.L., A. Alliman-Brissett, R.T. Lapan, S. Udipi, and D. Ergun, The Career-Related Parent Support Scale. Measurement \& Evaluation in Counseling \& Development (American Counseling Association), 2003. 36(2): p. 83.

6. $\quad$ Engberg, M.E. and G.C. Wolniak, College Student Pathways to the STEM Disciplines. Teachers College Record, 2013. 115(1): p. 27. 
7. Executive Office of the President, Increasing College Opportunity for Low-Income Students, 2014: http://www.whitehouse.gov/sites/default/files/docs/white_house_report_on_increasing college opportunit y_for low-income students 1-16-2014 final.pdf. p. 47.

8. Carrico, C., M. Boynton, H.M. Matusovich, and M.C. Paretti, Development of an interview protocol to understand engineering as a career choice for Appalachian youth, in American Society of Engineering Education2013: Atlanta, GA.

9. Lent, R.W. and S.D. Brown, Social cognitive approach to career development: An overview. The Career Development Quarterly, 1996. 44(4): p. 310-310.

10. Lent, R.W. and S.D. Brown, On conceptualizing and assessing social cognitive constructs in career research: A measurement guide. Journal of Career Assessment, 2006. 14(1): p. 12-35.

11. Markus, H. and P. Nurius, Possible selves. American Psychologist, 1986. 41(9): p. 954-969.

12. Oyserman, D. and H.R. Markus, Possible selves and delinquency. Journal of Personality and Social Psychology, 1990. 59(1): p. 112-125.

13. Carrico, C., H.M. Matusovich, and M.C. Paretti, Career Choice Reasons and Pathways of Rural Appalachian High School Students. Journal of Research in Rural Education, 2014. Under Review.

14. Boynton, M., C. Carrico, H. Matusovich, M. Paretti, and A.P. Taylor. Exposure matters: Understanding the experiences of rural cultures. in Frontiers in Education Conference, 2013 IEEE. 2013. IEEE.

15. Boynton, M., C. Carrico, M. Paretti, and H. Matusovich, Understanding Barriers to Engineering as a Career Choice for Appalachian Youth: Investigating the "heart" of the Region, in American Society of Engineering Education Southeast Section2013: Cookeville, Tn.

16. Boynton, M., People not Print: Exploring Engineering Future Possible Self Development in Rural Areas of Tennessee's Cumberland Plateau, in Engineering Education2014, Virginia Tech: Virginia Tech.

17. Carrico, C., Voices in the Mountains: A Qualitative Study Exploring Factors Influencing Appalachian High School Students' Engineering Career Goals, in Engineering Education2013, Virginia Polytechnic Institute and State University.

18. Carrico, C., H.M. Matusovich, M.C. Paretti, and M. Boynton. Maybe I am Interested in Engineering, Does that Matter? in American Society of Engineering Education. 2014. Indianapolis, IN.

19. Lee, W.C., H.M. Matusovich, and P.R. Brown, Measuring underrepresented student perceptions of inclusion within engineering departments and universities. International Journal of Engineering Education, 2014. 30(1): p. 150-165.

20. Capobianco, B.M., B.F. French, and H.A. Diefes-Dux, Engineering Identity Development Among PreAdolescent Learners. Journal of Engineering Education, 2012. 101(4): p. 698-716.

21. Trenor, J.M., Influences for selecting engineering: Insights on access to Social Capital from two case studies. Frontiers in Education (FIE) Conference, 2008: p. F4B-1-F4B-6.

22. Goode, J., If You Build Teachers, Will Students Come? The Role of Teachers in Broadening Computer Science Learning for Urban Students. Journal of Educational Computing Research, 2007. 36(1): p. 65-88.

23. Trenor, J.M. A Phenomenological inquiry on the major choice processes of an overlooked demographic: First generation college students in engineering. in Research in Engineering Education 2009. Palm Cove, QLD. 
24. McGee, E.O., "You Would Not Believe What I Have to Go Through to Prove My Intellectual Value!" Stereotype Management Among Academically Successful Black Mathematics and Engineering Students. American educational research journal, 2011. 48(6): p. 1347-1389.

25. Holmes, S., A. Redmond, J. Thomas, and K. High, Girls Helping Girls: Assessing the Influence of College Student Mentors in an Afterschool Engineering Program. Mentoring \& tutoring for partnership in learning, 2012. 20(1): p. 137-150.

26. Slovacek, S.P., J.C. Whittinghill, S. Tucker, K.A. Rath, A.R. Peterfreund, G.D. Kuehn, and Y.G. Reinke, Minority Students Severely Underrepresented in Science, Technology Engineering and Math. Journal of STEM education, 2011. 12(1-2): p. 5-16.

27. Schultz, W.P., Patching the Pipeline: Reducing Educational Disparities in the Sciences through Minority Training Programs. Educational evaluation and policy analysis, 2011. 33(1): p. 20.

28. Marshall, S.K., Adolescent Possible Selves as Jointly Constructed in Parent-Adolescent Career Conversations and Related Activities. Identity (Mahwah, N.J.), 2008. 8(3): p. 185-204.

29. Dick, T.P. and S.F. Rallis, Factors and influences on High School Students' Career Choices. Journal of Research in Mathematics Education, 1991. 22(4): p. 281 - 292.

30. Valla, J.M. and W.M. Williams, Increasing achievement and higher-education representation of underrepresented groups in science, technology, engineering, and mathematics fields: A review of current K-12 intervention programs. Journal of Women and Minorities in Science and Engineering, 2012. 18(1): p. 21 53.

31. Valla, J.M. and W.M. Williams, Increasing Achievement and Higher-Education Representation of UnderRepresented Groups in Science, Technology, Engineering, and Mathematics Fields: A Review of Current K-12 Intervention Programs. 2012. 18(1): p. 21-53.

32. Hanesian, D., B.-A. Levelle, R. Cano, H. Kimmel, H. McCloud, D. Muldrow, . . R.P.T. Tomkins. Impact of K-16 Programs at New Jersey Institute of Technology. in American Society of Engineering Educatoin. 2004. Salt Lake City, Utah.

33. Gooden, F., M. Borrego, W. Edmister, T. Waller, and B. Watford. An Assessment of Long-Term Impacts of Three On-Campus k-12 Enrichment Programs. in American Society of Engineering Education. 2010. Louisville, Ky.

34. Faud, N.A., Career Linking: An Intervention to Promote Math and Science Career Awareness. Journal of Counseling and Development, 1995. 73(5): p. 527-534.

35. Raising Public Awareness of Engineering, ed. L.A. Davis and R.D. Gibbin2002: The National Academies Press.

36. Ross, M.C. PK-12 Counselors Knowledge, Attitudes, and Behaviors Related to Gender and Stem. in American Society of Engineering Education. 2012. San Antonio, Texas.

37. Rea, L.M. and R.A. Parker, Designing and Conducting Survey Research: A Comprehensive Guide. 3rd ed2005, San Francisco, CA: John Wiley \& Sons.

38. Creswell, J.W., Research design: Qualitative, quantitative, and mixed methods approaches. 3rd ed2009, Thousand Oaks, CA: Sage Publications, Inc.

39. Collins, D., Pretesting survey instruments: An overview of cognitive methods. Quality of Life Research, 2003. 12(3): p. 229-238. 
40. Overview of Public Elementary and Secondary Schools and Districts: School Year 1999 - 2000. 2001 retrieved January 8, 2015]; Available from: http://nces.ed.gov/pubs2001/overview/table05.asp.

41. Carrico, C., H. Matusovich, and M.C. Paretti, High School Student Preparedness for College and Career Goals, in American Educational Research Association2014: Philadelphia, PA.

42. Carrico, C. and H.M. Matusovich, Appalachian High School Student Knowledge of the College Process for STEM-H Career Goals Journal of Women and Minorities in Science and Engineering, Manuscript in Review, 2014. 